\title{
The Use of Evidence by Decision-Making Committees
}

\author{
Ali Soroush' ${ }^{1}$, Mohammad Mohseni' ${ }^{2}$ Saeed Komasi ${ }^{1}$, Nadia Baharirad ${ }^{1}$, Farideh Moradi ${ }^{*}$ \\ ${ }^{1}$ Life Style Modification Research Center, Imam Reza Hospital, Kermanshah University of Medical Sciences, Kermanshah, \\ Iran \\ ${ }^{2}$ Health Management and Economics Research Center, Iran University of Medical Sciences, Tehran, Iran \\ ${ }^{3}$ Department of Health Services Management, School of Health Management and Information Sciences, Iran University \\ of Medical Sciences, Tehran, Iran
}

*Corresponding Author: Farideh Moradi, Ph.D. Candidate, Department of Health Services Management, School of Health Management and Information Sciences, Iran University of Medical Sciences, Tehran, Iran. Tel: +98-9138760502, Email: moradi336@gmail.com

\section{Dear Editor,}

By evidence, we mean systematic and extensive studies conducted to enhance knowledge and evidence-based policymaking (EBP), or evidence-based decision-making, an approach that helps individuals make decisions with more information and use the best evidence to establish, implement, and develop policies. ${ }^{1}$ Evidence-based policymaking is a complex of methods giving information to the process of policymaking rather than directly affecting the policies' probable goals. It is based on the idea that, in decision making, the existing information evidence should be exploited; moreover, the information used should have logical analysis. ${ }^{2}$ Hospital centers are the pillars of the health system in each country, and reforming the health sector without addressing such community centers and improving their performance would not be possible. ${ }^{3}$

One policy of the Ministry of Health for providing better performance and improving services in hospitals both qualitatively and quantitatively is to set up hospital committees. The hospital manager needs to establish hospital committees to plan, organize, guide, and control hospital activities. ${ }^{4}$ Groups and committees are usually set up to coordinate activities or accomplish a certain goal. Committees play a significant role in following up on the procedure of improving hospital services and the regular and continuous assessment of hospital activities; they are established to strengthen functions and solve all existing problems and hardships. ${ }^{5}$ Since hospital committees are regarded by hospital managers and owners as think tanks and as the advisory and decision-making arms of hospitals, obviously, optimal decisions made by such a committee can be effective in achieving the goals of the hospital and correcting its problems. Therefore, it is suggested that evidence from other countries on the issue of decisionmaking should initially be assessed with regard to the economic, social, and political conditions of the country. Furthermore, the conditions dominating in a hospital must be considered in making the final decision.

\section{Author's Contributions}

All authors contributed equally to this paper.

\section{Conflict of Interest Disclosures}

We declare that there is no conflict of interest.

Ethical Approval

Not applicable.

\section{References}

1. Davies HTO, Nutley SM, Smith PC. What Works? Evidence Based Policy and Practice In Public Services. Bristol: The Policy Press; 2005.

2. Pour Shirvani SN, Mouodi S. Evidenced-based in policymaking in health system and its achievements and challenges in Iran . Babol: Babol University of Medical Science; 2013:37. [Persian].

3. Asefzadeh S. Management and Hospital Research. Qazvin: Qazvin University of Medical Science Publication; 2003. [Persian].

4. Mosadegh Rad AM. Principles of health care services administration. 1st ed. Tehran; Tehran Dibagaran artistic and cultural institute; 2003:562-563. [Persian].

5. Ministry of Health and Medical Education. Drug and treatment deputy Instructions about hospital committees. Tehran: MoHME; 1997:181. [Persian].

Copyright (C) 2017 The Author(s). This is an open-access article distributed under the terms of the Creative Commons Attribution License (http:// creativecommons.org/licenses/by/4.0), which permits unrestricted use, distribution, and reproduction in any medium, provided the original work is properly cited. 